\title{
Eurídice Figueiredo - A literatura como arquivo da ditadura brasileira
}

Rio de Janeiro: 7Letras, 2017

Berttoni Cláudio Licarião ${ }^{1}$

A ficção produzida no Brasil nos últimos anos representa um grande desafio crítico-metodológico, cuja complexidade se manifesta não apenas de uma perspectiva temática ou formal, mas principalmente no estudo das filigranas de cada obra, plurissignificativas e multifacetadas. A leitura dos principais panoramas que se propuseram a apresentar a literatura brasileira dos últimos anos revela um conjunto ficcional que é, em síntese, urbano e regional, marginal e hiper-realista, fronteiriço e histórico, que explora o indivíduo e o simulacro, que dialoga com a tradição literária e subverte gêneros, pós-utópico e heteróclito.

Há, no entanto, um recorte que aos poucos vem ganhando corpo e fortuna crítica especializada, a literatura sobre os anos de autoritarismo político. Quais obras compõem esse recorte, como elas fornecem elementos de análise para melhor esclarecer o presente e de que maneira representam um dever em relação às vítimas e à sociedade em geral são os questionamentos que orientam A literatura como arquivo da ditadura brasileira.

Publicado no início de 2017, o livro de Eurídice Figueiredo concentra-se no estudo de pouco mais de 50 anos de uma produção literária que trata, direta ou indiretamente, da história do Brasil entre as décadas de 1960 e 1980. O escopo da pesquisa empreendida pela professora da Universidade Federal Fluminense é, portanto, bastante amplo. Compreende desde lançamentos mais recentes, como as obras premiadas de Maria Valéria Rezende (Outros cantos) e Julián Fuks (A resistência), quanto livros publicados durante os anos de repressão, a exemplo dos romances de Antonio Callado, Carlos Heitor Cony e Ignácio de Loyola Brandão. É importante ressaltar, todavia, que não se trata de um recenseamento exaustivo das obras produzidas sobre o assunto: o recorte em questão enfoca a reelaboração da experiência traumática da ditadura e a manutenção dessa memória na coletividade. Tendo isso em vista, a autora divide o corpus de sua pesquisa em três períodos: o de 1964 a 1979 compreende obras caracterizadas pela tônica

${ }^{1}$ Doutorando em literatura na Universidade de Brasília (UnB), Brasília, DF, Brasil. E-mail: berttoni@gmail.com 
"ora prospectiva e utópica, ora distópica diante do fracasso dos projetos revolucionários" (Figueiredo, 2017, p. 47); o segundo, da produção entre 1980 e 2000, diferencia-se pela predominância de relatos autobiográficos de presos e exilados políticos; e, por fim, o terceiro período acompanha a produção literária dos últimos anos, marcada pela análise retrospectiva e beneficiária da Comissão Especial sobre Mortos e Desaparecidos Políticos (criada em 1995) e, posteriormente, da Comissão Nacional da Verdade, sancionada em 2012.

Aproveitando-se de um lugar de enunciação ainda sob o impacto do golpe parlamentar de 2016, o texto de Eurídice Figueiredo articula-se como um discurso de resistência que aventa a necessidade de preservação da memória traumática do país. A partir das noções de arquivo de Derrida e Foucault, associadas às contribuições de Walter Benjamin sobre a escrita da história, a autora compreende o conjunto de narrativas ficcionais e não ficcionais publicados desde 1964 como documentos de valor, capazes de inventariar não somente as feridas e cicatrizes, mas também o impacto das torturas, mortes $\mathrm{e}$ desaparecimentos no cotidiano e no imaginário de milhares de brasileiros. A literatura aparece, destarte, como um "elemento ativo na transmissão da memória para que não se apague aquilo que afetou a vida das pessoas" (Figueiredo, 2017, p. 46).

Também compõem o horizonte teórico de A literatura como arquivo da ditadura brasileira as contribuições do filósofo Paul Ricœur sobre memória e responsabilidade, anistia e amnésia. O resgate dessa discussão é pertinente, uma vez que Eurídice Figueiredo contrapõe a prática literária à pulsão arquiviolítica dos militares e ao apagamento da história engendrado pela Lei da Anistia (1979). Com a ajuda dos arquivos da ditadura propriamente ditos - propiciados pela ação de projetos como Brasil: nunca mais (1985) e da Comissão Nacional da Verdade (2012-2014) - a literatura é capaz de transformar o trauma em experiência estética compartilhada, cumprindo com aquele dever da memória, "o dever de fazer justiça, pela lembrança, a um outro que não o si” (Ricœur, 2007, p. 101).

Para Eurídice Figueiredo, esse movimento ao mesmo tempo orgânico e político da literatura surge na contracorrente da morosidade do Estado brasileiro, que se recusa a revisar a lei da anistia e punir os culpados por crimes contra a humanidade, além de continuar "a praticar os mesmos crimes de tortura e morte, não mais por delitos de opinião, mas contra cidadãos das classes desfavorecidas que tenham ou não praticado 
pequenos crimes" (Figueiredo, 2017, p. 39). O discurso da literatura expõe essa cultura da impunidade ao estabelecer vínculos entre passado e presente. É o que faz, por exemplo, Marcelo Rubens Paiva, em Ainda estou aqui (2015) quando coloca lado a lado o desaparecimento do pedreiro Amarildo Dias de Souza, em 14 de julho de 2013, e o sequestro de seu pai, em janeiro de 1971. As duas mortes, assim aproximadas, revelam a alarmante perpetuidade de práticas criminosas do Estado por mais de 40 anos. É contra esses "vácuos de justiça" que a literatura das últimas décadas tem reagido, conclui a autora.

Além das diferentes formas de reelaboração do trauma que representou a ditadura brasileira no campo literário, o edifício crítico de Eurídice Figueiredo não dispensa contribuições de outras áreas de conhecimento. A autora estende suas leituras também à produção de jornalistas, historiadores e críticos literários, arregimentando num mesmo espaço a multiplicidade de discursos críticos que revolvem as entranhas da ditadura civil-militar brasileira. A autora dialoga com os estudos de Flora Süssekind (1985), Regina Dalcastagnè (1996), Tânia Pellegrini (1996), Malcolm Silverman (2000) e Idelber Avelar (2003), bem como apresenta, ainda que brevemente, textos de jornalistas e historiadores que trouxeram significativas contribuições à compreensão do período, a exemplo das obras de Marcelo Godoy (A casa da vovó, 2014), Lucas Figueiredo (Lugar nenhum: militares e civis na ocultação dos documentos da ditadura, 2015), Daniela Arbex (Cova 312, 2015) e Rafael Guimaraens (O sargento, o marechal e o faquir, 2016). A leitura desses textos reforça a noção da literatura sobre a ditadura como um "palimpsesto da dor", construída sobre os rastros de vidas suprimidas:

Aqueles que tentam hoje escrever sobre o passado da ditadura se apoiam, de um lado, nas lembranças pessoais e familiares, de outro lado, em informações levantadas e já compiladas nos diferentes arquivos. Muitos familiares de desaparecidos e mortos fizeram suas buscas, contribuindo para esclarecer os fatos e desmontar as farsas. $O$ trabalho de escavação não terminou, e a quantidade de livros publicados, sobretudo desde 2010, comprova que o trabalho de elaboração do trauma da ditadura continua (Figueiredo, 2017, p. 30).

A recensão das obras literárias que compõem o corpus de A literatura como arquivo encontra-se organizada por eixos temáticos. As narrativas do segundo período (1980-2000), por exemplo, são analisadas em dois 
grupos, "relatos autobiográficos" e "romances sobre exílio e retorno ao país natal". Já os livros do terceiro recorte temporal, que vai de 2001 até 2016, dividem-se em categorias mais específicas, ainda que por vezes artificiais, como "romances com histórias cruzadas", "o Araguaia como fantasma", "romances e relatos memoriais", "Oban e operação Condor", "(auto)biografia de um cachorro" e "os filhos do exílio". A sistematização proposta é evidentemente problemática, porque elaborada a partir de critérios de seleção que não permanecem os mesmos entre uma categoria e outra (ora os romances são agrupados por tema, ora por estrutura narrativa ou origem dos autores etc.). Não obstante, Eurídice Figueiredo logra manter narrativas e categorias em diálogo aberto, sem perder de vista o foco nas representações do trauma ou na investigação do presente. Além dos autores já referidos, são também alvo de comentários as obras de Frei Betto, Renato Tapajós, Fernando Gabeira, Alfredo Sirkis, Álvaro Caldas, Luiz Roberto Salinas Fortes, Salim Miguel, Flávio Tavares, Ana Maria Machado, Godofredo de Oliveira Neto, Silviano Santiago, Marcus Veras, Míriam Leitão, Edney Silvestre, Liniane Haag Brum, Guiomar de Grammont, Adriana Lisboa, Maria Pilla, Beatriz Bracher, Edgard Telles Ribeiro, Ivone Benedetti e Paloma Vidal.

A ficção de Bernardo Kucinski é tratada num capítulo à parte. Caracterizadas por uma "escrita fragmentária e altamente elaborada", tanto K.: relato de uma busca quanto a coletânea Você vai voltar pra mim e outros contos (2014) e a sequência Os visitantes (2016) são, para a autora, exemplos de narrativas que conseguiram não somente falar dos efeitos da repressão de maneira inovadora, como se tornaram testemunhos bem-sucedidos dos crimes contra a humanidade cometidos durante $\mathrm{O}$ período. Logo, a análise detalhada de Eurídice Figueiredo atribui a K.: relato de uma busca um lugar proeminente na produção nacional, cujo valor estético e testemunhal contribui sobremaneira à formação de um arquivo literário sobre a ditadura:

O estilo do autor, enxuto e fragmentário, atinge a emoção do leitor sem apelar para o melodramático, pelo contrário, ele usa da ironia e do despojamento da linguagem para criar o ambiente absurdo, claustrofóbico e apavorante em que se viu o pai diante do sumiço da filha (Figueiredo, 2017, p. 143).

A leitura de relatórios e arquivos é, via de regra, bastante árida e desengajada. O testemunho e a ficção, por outro lado, ancorados na capacidade inerente à narrativa de articular o ser humano, são terrenos 
propícios à transformação. Para Figueiredo, "só numa dimensão ficcional é possível entrever nas dobras da história os interditos. Transmutar o vivido" (2017, p. 48). Ao se demitir do silêncio institucional e provocar formas de sentir o trauma, a literatura continua e ser a "maldição das ditaduras", nas palavras de Alberto Manguel (2009, p. 315), iluminando as zonas escuras da casa da memória. São esses focos de luz que Eurídice Figueiredo consegue capturar apesar do caráter panorâmico que às vezes compromete a verticalidade de suas análises (à exceção de K.: relato de uma busca, que é estudado a fundo).

A literatura como arquivo da ditadura brasileira articula com clareza práticas discursivas variadas sem, contudo, fazer da literatura refém de categorias crítico-epistemológicas. Até esta data, trata-se do que a crítica literária contemporânea dispõe de mais atual em termos de catalogação e comentário de obras brasileiras sobre a ditadura militar. Configura, desse modo, uma porta de entrada para estudantes e pesquisadores interessados na produção crítica e literária sobre os anos de repressão, tortura e desaparecimentos que marcaram os governos militares iniciados com o golpe de 64. O livro traz, ainda, à guisa de epílogo, uma versão revisada do texto "Minha terra tem palmeiras... e me expulsaram de lá (Geração 1968)", relato da autora sobre seus anos de exílio em Paris, originalmente publicado na coletânea Caminhando e contando (2015).

\section{Referências}

ARBEX, Daniela (2015). Cova 312. São Paulo: Geração.

AVELAR, Idelber (2003). Alegorias da derrota: a ficção pós-ditadorial e o trabalho de luto na América Latina. Tradução de Saulo Gouveia. Belo Horizonte: Editora da UFMG.

BENJAMIN, Walter (2000). Rua de mão única. Obras escolhidas II. São Paulo: Brasiliense.

DALCASTAGNÈ, Regina (1996). O espaço da dor: o regime de 64 no romance brasileiro. Brasília: Editora da UnB.

DERRIDA, Jacques (2001). Mal de arquivo: uma impressão freudiana. Tradução de Cláudia de Moraes Rego. Rio de Janeiro: Relume Dumará.

FIGUEIREDO, Eurídice (2017). A literatura como arquivo da ditadura brasileira. Rio de Janeiro: 7Letras. 
FIGUEIREDO, Lucas (2015). Lugar nenhum: militares e civis na ocultação dos documentos da ditadura. São Paulo: Companhia das Letras.

FOUCAULT, Michel (2009). A arqueologia do saber. Tradução de Luiz Felipe Baeta Neves. Rio de Janeiro: Forense Universitária.

GODOY, Marcelo (2014). A casa da vovó: uma biografia do DOI-CODI (19691991). 2. ed. São Paulo: Alameda.

GUIMARAENS, Rafael (2016). O sargento, o marechal e o faquir. Porto Alegre: Libretos.

MANGUEL, Alberto (2009). Uma história da leitura. Tradução de Pedro Maia Soares. São Paulo: Companhia das Letras.

PELLEGRINI, Tânia (1996). Gavetas vazias: ficção e política nos anos 70. São Carlos: Editora da UFSCar; Mercado de Letras.

RICOUER, Paul (2007). A memória, a história, o esquecimento. Tradução Alain François et al. Campinas: Editora da Unicamp.

SILVERMAN, Malcom (2000). Protesto e o novo romance brasileiro. Tradução de Carlos Araújo. Rio de Janeiro: Civilização Brasileira.

SÜSSEKIND, Flora (1985). Literatura e vida literária: polêmicas, diários \& retratos. Rio de Janeiro: Jorge Zahar.

Recebido em 5 de junho de 2017.

Aprovado em 9 de setembro de 2017. 